\title{
Prevalence of peptic ulcer in Helicobacter pylori positive blood donors
}

\author{
D Vaira, M Miglioli, P Mulè, J Holton, M Menegatti, M Vergura, G Biasco, R Conte, \\ R P H Logan, L Barbara
}

antibiotics, or corticosteroids or who is found to have a biochemical abnormality is not allowed to donate blood. Men are allowed to donate blood every three months and women every six months.

\section{METHODS}

Specific anti-H pylori IgG antibodies were measured by a previously validated ELISA technique using anti-human peroxidase labelled IgG conjugate with a sensitivity and specificity of $94 \% .{ }^{112}$ The results were expressed as the absorbance index (AI):

$$
A I=\frac{\text { mean OD value }(n=2) \text { of patient serum }}{\text { mean OD value }(n=2) \text { of reference serum }}
$$

where OD is the optical density at $405 \mathrm{~nm}$. An AI $>0.3$ for the IgG to $H$ pylori defined seropositivity. The serum from an $H$ pylori positive duodenal ulcer patient was used as reference serum for all the assays.

The first consecutive 162 blood donors with high titres of IgG to $H$ pylori were interviewed before endoscopy. They were questioned about the presence and frequency of upper gastrointestinal tract symptoms including indigestion, heartburn, nausea, and vomiting and about recent medication (consumption of antibiotics, $\mathrm{H}_{2}$ antagonists, antacids, and NSAIDs within the previous three months). After interview, consent for endoscopy was sought. At endoscopy blood was taken for repeat serology. All endoscopies were performed under local anaesthesia (xylocaine), by the same investigator (DV), and using an Olympus videoendoscope GIF-100.

A gastric or duodenal ulcer was defined as mucosal ulceration $>5 \mathrm{~mm}$ in diameter and erosive duodenitis as multiple, discrete, focal red spots $<5 \mathrm{~mm} .{ }^{13}$ Four antral biopsy specimens were taken with endoscopic biopsy forceps (Olympus FB 24Q) - two for histology (haematoxylin and eosin and Giemsa stains), one for culture, and one for the urease test (CP-TEST; Gist-Brocades Farma, SpA, Italy). ${ }^{14}$ Histology and culture were done without knowledge of the subject's $H$ pylori status or the results of endoscopy. The histological appearances were graded according to Whitehead. ${ }^{\text {is }} H$ pylori was diagnosed by identification of the organism on histology and a positive urease test. ${ }^{1+}$

A control group of consecutive and concurrent patients with dyspepsia ( $n=219$; male/female: 123/96; age range 18-65, mean 46 years) endoscoped by the same operator (DV), were used as age and sex matched controls because it was clearly unjustified and unethical to use seronegative asymptomatic blood donors. The study 
was approved by S Orsola Hospital ethical committee and informed consent for endoscopy was obtained from all subjects.

Statistical analysis was by $\chi^{2}$ test.

\section{Results}

Altogether 422 of 1010 blood donors (42\%) had serological evidence of $H$ pylori infection. The prevalence of high IgG titres increased with age (Fig 1), but was not correlated with cigarette or alcohol consumption, sex, blood group, or social class. None of the donors drank more than $75 \mathrm{~g} /$ day of alcohol, although $23 \%$ smoked $>10$ cigarettes/day.

Postal questionnaires were sent to the first 180 consecutive blood donors, 162 responded $(90 \%)$ and $128(79 \%)(\mathrm{M} / \mathrm{F}: 88$ of 40 , age range $18-65$, mean 48 years) consented to endoscopy. Twenty four of 34 refused endoscopy on the advice of their general practitioner and 18 subjects were no longer resident in Bologna and could not be contacted.

At endoscopy, $H$ pylori infection was confirmed in 121 of 128 (95\%) seropositive donors by both Giemsa staining and urease test, and in 97 of $121(80 \%)$, culture was also positive. Only seven of 128 previously seropositive donors (4\%) (age range 31-63 years, median 48 years) had no evidence of $H$ pylori and all had normal histology. On repeat serology five of seven had an AI of $<0 \cdot 3$, while in two of seven the titre was similar to the previous level. None of the five patients had been investigated previously for

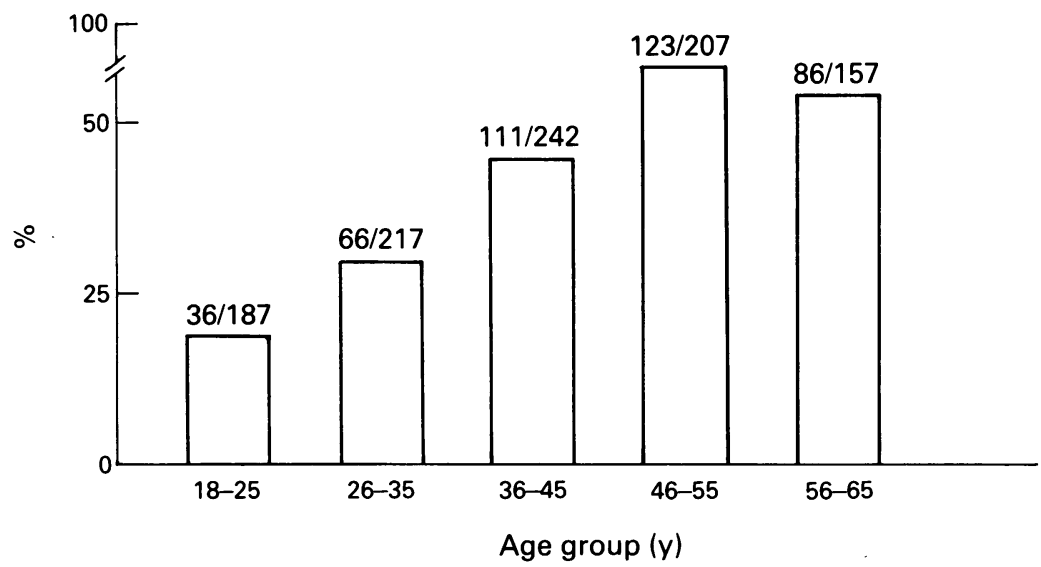

Figure 1: IgG seroprevalence of Helicobacter pylori in 1010 blood donors.

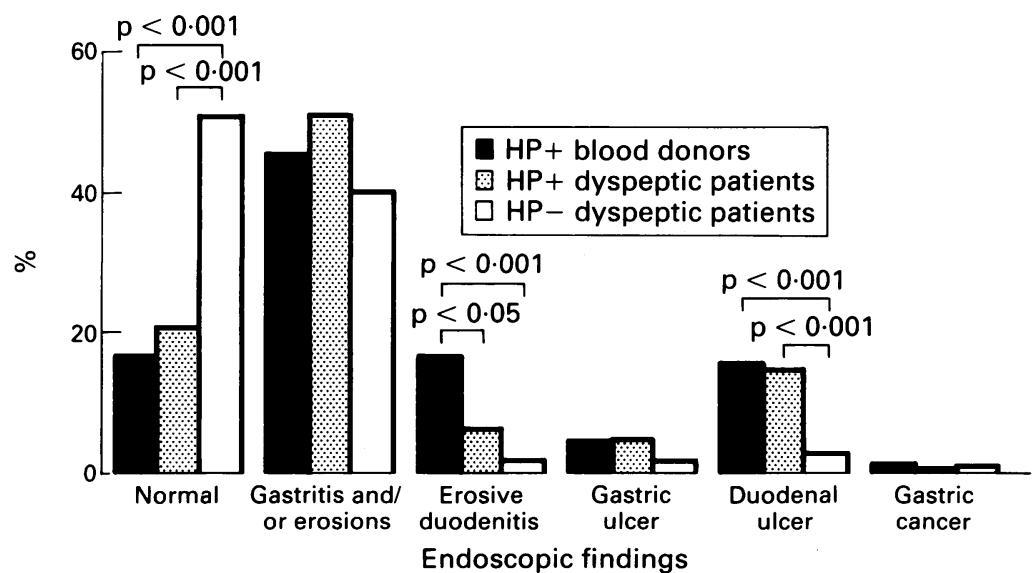

Figure 2: Endoscopic findings in Helicobacter pylori $(H P)$ positive blood donors compared with $\mathrm{H}$ pylori positive and $\mathrm{H}$ pylori negative dyspeptic patients. dyspepsia or received anti- $H$ pylori therapy, nor were they taking antibiotics or bismuth containing compounds at the time of endoscopy, suggesting that spontaneous clearance of $H$ pylori had probably occurred.

Endoscopy of 121 patients with confirmed chronic $H$ pylori infection showed gastritis/antral erosions in 58 (45\%), erosive duodenitis in 21 $(16 \%)$, duodenal ulcer in $20(16 \%)$, gastric ulcer in six $(5 \%)$, and gastric cancer in two patients (one leimyosarcoma (T1, N0, M0), one adenocarcinoma (T3, N2, M1)). In 21 of $121(16 \%)$ seropositive subjects the endoscopic findings were normal. In the seven donors with no evidence of $H$ pylori infection endoscopy was normal in five and showed antral gastritis in two. No correlation was found between the IgG titres and the endoscopic findings or between blood group status and duodenal ulcer $(0+n=6,0-$ $n=2, B+n=2, A+n=8, A-n=2)$. The endoscopic findings in the age matched $H$ pylori positive controls with dyspepsia $(n=120 ; M / F$ : $71 / 49$, age range $18-65$, mean 46 years) were broadly similar (Fig 2). Compared with seropositive blood donors, however, erosive duodenitis was significantly less frequent $(\mathrm{n}=8,7 \% \mathrm{v}$ $16 \%, \mathrm{p}<0.05$ ). In the $H$ pylori negative controls with dyspepsia $(\mathrm{n}=99 ; \mathrm{M} / \mathrm{F}$ : 52/47; age range $18-65$, mean 46 years), 51 of $99(51 \%)$ had a normal endoscopy compared with $16 \%$ and $21 \%$ of seropositive donors and $H$ pylori positive patients with dyspepsia respectively $(\mathrm{p}<0.001)$, and only three $(3 \%)$ had duodenal ulcers significantly fewer $(p<0.001)$ than either seropositive donors (16\%) or $H$ pylori positive patients with dyspepsia $(n=18,15 \%)$. There were no significant differences in age, social class, and cigarette or alcohol consumption in seropositive endoscoped blood donors, seronegative and seropositive donors, nor between $H$ pylori positive dyspeptic and $H$ pylori negative dyspeptic controls. Table I shows the social class distribution in the study population. No significant differences were found between the antibody responses of the seropositive blood donors and the $H$ pylori positive controls with dyspepsia (Fig 3).

Only two of 20 seropositive blood donors with a duodenal ulcer complained of dyspepsia at the time of endoscopy. At interview, a further six donors later found to be seropositive complained of current dyspepsia, but endoscopy showed only antral gastritis $(n=4)$ or erosive duodenitis $(n=2)$. All eight patients had been investigated for dyspepsia in the previous year and none had been taking NSAIDs; a further 35 patients had also been investigated previously for dyspepsia by their general practitioner (barium meal $n=25$, upper gastrointestinal endoscopy $n=18$ ) a median (range) of 4 (1-32) years previously. Table II shows the previous findings compared with present ones.

\section{Discussion}

This and previous studies have shown the accuracy of serology in detecting $H$ pylori and that seropositivity is associated with chronic non-autoimmune gastritis. ${ }^{16}$ The earlier validation studies were done using sera from dyspeptic 
TABLE I Distribution in social classes (\%)

\begin{tabular}{lccccc}
\hline $\begin{array}{l}\text { Social class } \\
\text { grouping }\end{array}$ & $\begin{array}{l}\text { Seronegative } \\
\text { blood donors }\end{array}$ & $\begin{array}{l}\text { Seropositive } \\
\text { blood donors }\end{array}$ & $\begin{array}{l}\text { Seropositive } \\
\text { endoscoped } \\
\text { blood donors }\end{array}$ & $\begin{array}{l}\text { H pylori } \\
\text { positive } \\
\text { controls }\end{array}$ & $\begin{array}{l}\text { H pylori } \\
\text { negative } \\
\text { controls }\end{array}$ \\
\hline I & $18(3)$ & $13(3)$ & $4(3)$ & $4(3)$ & $4(4)$ \\
II & $55(9)$ & $40(9)$ & $12(9)$ & $10(8)$ & $9(9)$ \\
IIIN & $217(37)$ & $155(37)$ & $47(37)$ & $42(35)$ & $35(35)$ \\
IIIM & $69(12)$ & $49(12)$ & $15(12)$ & $14(12)$ & $12(12)$ \\
IV & $229(39)$ & $165(39)$ & $50(39)$ & $50(42)$ & $39(39)$ \\
V & 0 & 0 & 0 & 0 & 0 \\
Total & 588 & 422 & 128 & 120 & 99 \\
\hline
\end{tabular}

ulcer to be $6 \%$, while a similar study from India has suggested that the point and lifetime prevalences of duodenal ulcer were $5 \%$ and $11 \%$ respectively. ${ }^{18}$ These early studies, however, antedate the discovery of $H$ pylori and appreciation of its role in the aetiology of duodenal ulcer. Thus, differences in and between popualtions in ulcer prevalence may have been due to differences in the prevalence of $H$ pylori infection.
Figure 3: IgG absorbance index in relation to different endoscopic findings in $\mathrm{H}$ pylori $(H P)$ positive blood donors and $\mathbf{H}$ pylori positive dyspeptic patients.

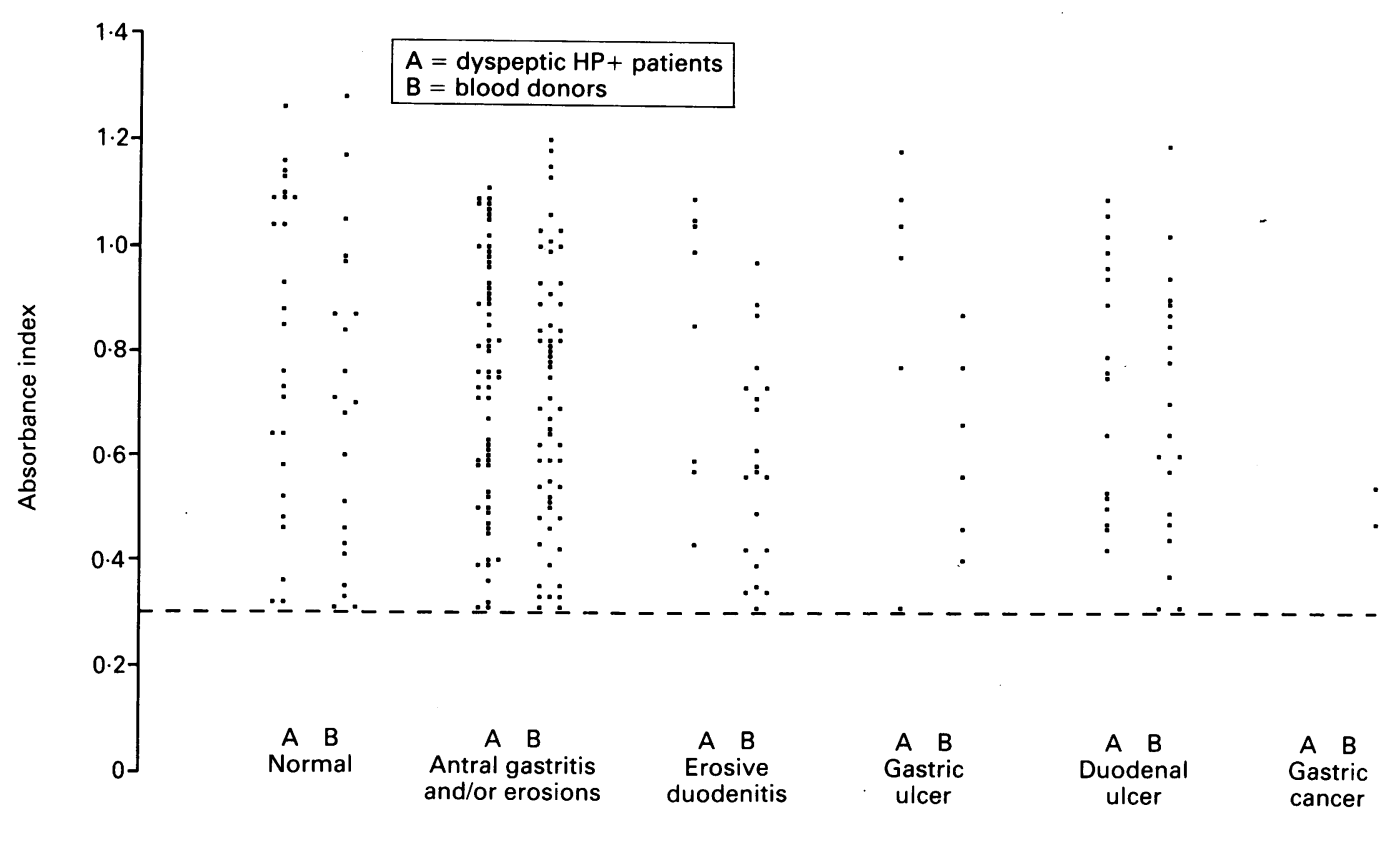

TABLE II Present findings in 43 blood donors previously investigated for dyspepsia

Current status
$\begin{array}{lllllll}N & A G & A E & E D & G U & D U & \text { Symptoms }\end{array}$

\begin{tabular}{|c|c|c|c|c|c|c|c|c|}
\hline \multirow{2}{*}{\multicolumn{9}{|c|}{ Those who had previously undergone upper gastrointestinal endoscopy: }} \\
\hline & & कात & & & & & \multirow{3}{*}{$\begin{array}{l}2 \\
1 \\
2\end{array}$} & \multirow{3}{*}{$\begin{array}{l}1 \text { burning pain, } 1 \text { heartburn, } 1 \text { nause } \\
1 \text { burning pain } \\
1 \text { burning pain }\end{array}$} \\
\hline \multirow{2}{*}{$\begin{array}{l}\text { Past } \\
\text { findings }\end{array}$} & $\mathrm{AG}=7$ & & 2 & 1 & \multirow[t]{2}{*}{2} & & & \\
\hline & $\begin{array}{l}E D=1 \\
D U=5\end{array}$ & & 1 & 2 & & & & \\
\hline \multirow{4}{*}{$\begin{array}{l}\text { Those wh } \\
\text { Past } \\
\text { findings }\end{array}$} & d previou & & gon & & & & & \\
\hline & $\begin{array}{l}N=13 \\
A G=5\end{array}$ & 3 & 6 & 4 & 2 & 1 & 1 & 1 heartburn \\
\hline & $\mathrm{ED}=0$ & & 2 & 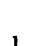 & 1 & 1 & 1 & \\
\hline & $\mathrm{DU}=7$ & & 2 & 1 & 1 & 1 & 2 & 1 burning pain, 1 heartburn nausea \\
\hline
\end{tabular}

$\mathrm{N}=$ normal; $\mathrm{AG}=$ antral gastritis; $\mathrm{AE}=$ antral erosions; $\mathrm{ED}=$ =rosive duodenitis; $\mathrm{GU}=$ gastric ulcer; $\mathrm{DU}=$ duodenal ulcer.

outpatients referred for endoscopy, however, and therefore only limited conclusions could be drawn about the clinical importance of a positive result in the general population. Seropositivity (or a positive breath test) in an asymptomatic subject was generally assumed to be clinically irrelevant and did not need further investigation. Indeed, seropositivity or a positive breath test in an asymptomatic individual has been used as sufficient inclusion criteria for control groups in clinical research. Our results suggest that these previous assumptions are no longer valid and challenge our understanding of the natural history of $H$ pylori infection and duodenal ulcer.

Previously, the cumulative life time risk of duodenal ulcer for any individual (based mainly on radiological diagnosis and without considering $H$ pylori status) was considered to be about $10 \% .{ }^{17}$ More accurate endoscopic data from random samples of an Estonian population have shown the cumulative $\mathbf{1 0}$ year risk for duodenal
Therefore the Estonian endoscopic biopsy material has been re-examined and it has been shown that $95 \%$ of the study population were infected with $H$ pylori. A more recent study, from a population with an $H$ pylori prevalence of $55 \%$ and of a similar mean age to that in our study, found a duodenal ulcer in 24 of $171(14 \%)$ $H$ pylori positive dyspeptic patients referred for endoscopy. ${ }^{19}$ Similarly, a large study of dyspeptic patients undergoing upper gastrointestinal endoscopy in China, where the $H$ pylori prevalence is $65 \%$, found that $19 \%$ had a duodenal ulcer ${ }^{20}$ and there was a 3:1 male preponderance. All these recent studies were on patients referred for dyspepsia, however, and are therefore not representative of the general population.

Although blood donors may not be representative either, because of self selection or financial reward for donation (unlikely for Italy), we consider our study population valid because the age and social class distributions were similar to those in the general population of Bologna and because only $6 \%$ had complained of dyspepsia in the preceding 12 months, a figure similar to that in other reports on the prevalence of dyspepsia in the community. In contrast to the data of Sitas $e t$ $a l,{ }^{8}$ we did not find any correlation with social class. This could be due to the fact that the standard of living in the city of Bologna is not related to the economic status of the inhabitants.

Recent Norwegian data, which took into account both the presence and absence of either dyspepsia or $H$ pylori infection, compare strikingly with our own and other data. Bernersen $e t$ $a l^{2122}$ found that in dyspeptic subjects, $48 \%$ of whom had $H$ pylori, endoscopy showed duodenal 
ulcer in only $3 \cdot 8 \% v 1 \%$ of asymptomatic subjects, $36 \%$ of whom had $H$ pylori. Different endoscopic criteria for duodenal ulcer, NSAID usage, or observer variation may account for some of the variation in ulcer prevalence. Similarly, in a study of Tibetan monks with a high prevalence of dyspepsia (69\%) and $\mathrm{H}$ pylori infection (75\%), Katelaris et al found a $6.6 \%$ endoscopic point prevalence for peptic ulcer. ${ }^{23}$

Intrapopulation comparison of our data shows that duodenal ulcer is as common in $H$ pylori patients with dyspepsia as in the asymptomatic seropositive blood donors. Moreover, the AIs were identical in all positive subjects, regardless of symptoms or endoscopic findings (Fig 3).

A history of peptic ulcer is not an exclusion criterion for giving blood in Italy and indeed peptic ulcers were present in 12 of $43(28 \%)$ donors investigated previously for dyspepsia. Five of 12 were found to have a duodenal $(n=4)$ or gastric ulcer $(n=1)$ (Table II). If we exclude these five subjects the prevalence of peptic ulcer in the asymptomatic $H$ pylori positive donors is still $16 \%$, a prevalence considerably higher than that previously reported.

Finally, these results also suggest that the measurement of IgG antibodies to $H$ pylori are helpful in detecting 'silent' peptic ulcer, which confirms previous reports that screening for $H$ pylori infection is an effective way of reducing the endoscopic workload and that dyspepsia is a poor guide to the diagnostic value of endoscopy. ${ }^{19} 24$

Although it is now generally accepted that $H$ pylori is a pathogen and not a commensal infection, sceptics still claim that $H$ pylori is not clinically important, because only a very small proportion of infected patients develop duodenal ulcer.

$H$ pylori associated peptic ulcer occurs more frequently than previously recognised and suggests that $H$ pylori infection, even in the absence of symptoms, is of far greater clinical relevance than originally thought.

The authors thank Pfizer Inc, Rome; Glaxo SpA, Verona; and Lepetit SpA, Milan (Italy) for financial support: Mrs Graziella Venturi for her valuable secretarial work with the blood donors subjects; and Luigi Gatta for his help in the elaboration of ELISA subjects;
I Vaira D, Holton J, Miglioli $M$, Mulè $P$, Menegatti $M$, Barbara L. Helicobacter pylori and other spiral organisms. Current Opinion in Gastroenterol 1992; 8: 918-26.

2 Forman D, Newell DG, Fullerton F, et al. Association between infection with Helicobacter pylori and risk of gastric cancer: evidence from a prospective investigation. BMF 1991; 302: 1302-5.

3 Parsonnet J, Friedman GD, Vandersteen P, et al. Helicobacter pylori infection and the risk of gastric carcinoma. New Engl F Med 1991; 325: 1127-31.

4 Jones DM, Eldrige J, Fox AJ, et al. Antibody to the gastric campylobacter-like organisms (Campylobacter pyloridis)clinical correlations and distribution in the normal population. $\mathcal{F}$ Med Microbiol 1989; 22: 57-62.

5 Morris A, Nicholson G, Lloyd GL, et al. Seroepidemiology of Campylobacter pyloridis. N Z Med f 1986; 99: 657-9.

6 Megraud F, Brassens-Rebbe M-P, Denis F, et al. Seroepidemiology of $C$ pylori infection in various populations. 7 Clin Microbiol 1989; 27: 1870-73.

7 Mitchell HM, Lee A, Carrick J. Increased incidence of Campylobacter pylori infection in gastroenterologists: further evidence to support person-to-person transmission of C pylori. Scand F Gastroenterol 1989; 24: 396-400.

8 Sitas F, Forman D, Yarnell JWG, et al. Helicobacter pylori infection rates in relation to age and social class in a population of Welsh men. Gut 1991; 32: 25-8.

9 Graham DY, Malaty HM, Evans DG, et al. Epidemiology of Helicobacter pylori in an asymptomatic population in the United States. Gastroenterology 1991; 100: 1495-501.

10 Office of Population Censuses and Surveys. Standard Occupational Classification. Government Statistical Service, Occupational Classification
London: HMSO, 1991 .

11 Vaira D, Holton J. Serum immunoglobulin G antibody levels for Campylobacter pylori diagnosis. Gastroenterology 1989; 97: 1069-70.

12 Oderda G, Vaira D, Holton J, et al. Helicobacter pylori in children with peptic ulcer and their families. Dig Dis Sci 1991; 36: 572-6.

13 Blakstone MO. Endoscopic interpretation. New York: Raven Press, 1984.

14 Vaira D, Holton J, Osborn J, et al. Endoscopy in dyspeptic patients: is gastric mucosal biopsy useful? Am f Gastroenterol 1990; 85: 701-4.

15 Whitehead R. Mucosal biopsy of the gastrointestinal tract. In: Bennington JL, ed. Major problems in pathology. Vol 3. Bennington JL, ed. Major problems in patho

16 Perez-Perez GI, Dworkin BM, Chodos JE, Blaser MJ. Campylobacter antibodies in humans. Ann Intern Med 1988; 58: $992-8$.

17 Sipponen P, Varis K, Frankl O, Korri U-M, Seppa K, Siurala $M$. Cumulative ten year risk of symptomatic duodenal and gastric ulcer in patients with or without chronic gastritis. Scand F Gastroenterol 1990; 25: 966-73.

18 Khurro MS, Mahajan R, Zargar SA, Javid G, Munshi S. Prevalence of peptic ulcer in India: an endoscopic and epidemiological study in urban Kashmir. Gut 1989; 30: $930-4$.

19 Sobala GM, Crabtree JE, Pentith JA, et al. Screening dyspepsia by serology to Helicobacter pylori. Lancet 1991; 338: pepsia.

$20 \mathrm{Li}$ YY, Hu MD, Du GG, Hazel SL. The prevalence of Helicobacter pylori infection in the Peoples Republic of China. Am $\mathcal{F}$ Gastroenterol 1991; 86: 446-9.

21 Bernersen B, Johnsen R, Straume B, et al. Towards a true prevalence of peptic ulcer: the Sorreisa gastrointestinal disorder study. Gut 1990; 31: 989-92.

22 Bernersen B, Johnsen R, Straume B, et al. Is Helicobacter pylori the cause of dyspepsia? $B M \mathcal{F}$ 1992; 304: 1276-9.

23 Katelaris PH, Tippett G, Brennen R, Norbu P, Farthing MJG. Prevalence of Helicobacter pylori and peptic ulcer and relation to symptoms in a Tibetan refugee population in southern India. Gut 1991; 32: A556.

24 Johnsen R, Bernersen B, Straume B, Forde OH, Bostad L, Burhol PG. Prevalences of endoscopic and histological findings in subjects with and without dyspepsia. BMJ 1991; 302: 749-52. 